\title{
Primary vitrectomy for pseudophakic and aphakic retinal detachments
}

\begin{abstract}
Purpose To evaluate primary vitrectomy for the treatment of pseudophakic and aphakic retinal detachments. Primary vitrectomy may enable better identification of retinal breaks than scleral buckling procedures.

Methods A prospective study was performed of primary vitrectomy for the treatment of 25 consecutive cases of pseudophakic and aphakic retinal detachment.

Results The primary retinal reattachment rate was $84 \%$ (21 eyes). Surgical failure resulted from new/missed retinal breaks ( 2 eyes) and proliferative vitreoretinopathy ( 2 eyes). The final retinal reattachment rate with further surgery was $96 \%$ (24 eyes). There were 7 macula-on detachments which all retained their presenting visual acuity. A visual acuity of $6 / 18$ or better was achieved by $56 \%$ of the 18 macula-off detachments. Visualisation of the peripheral retina was impaired in 17 eyes and procedures to improve visualisation were performed in 7 eyes. Retinal breaks were detected in 16 eyes at surgery that had not been identified pre-operatively. Raised intraocular pressure was the most common complication, affecting $\mathbf{1 0}$ eyes in the early post-operative period.

Conclusions Primary vitrectomy offers certain advantages in the treatment of pseudophakic and aphakic retinal detachments. A controlled study is required to determine whether primary vitrectomy achieves a better outcome than scleral buckling procedures for these retinal detachments.
\end{abstract}

Key words Aphakia, Cataract extraction, Lenses - intraocular, Pseudophakia, Retinal detachment, Vitrectomy

Sceral buckling procedures for pseudophakic and aphakic retinal detachments may be compromised by poor visualisation of the peripheral retina. ${ }^{1-7}$ This can result from anterior or posterior capsular opacification, cortical lens remnants, reflexes from the intraocular lens surface, refraction at the intraocular lens rim, and inadequate pupillary dilatation. Impaired visualisation of the peripheral retina may be responsible for scleral buckling procedures having a lower primary retinal reattachment rate in pseudophakic and aphakic eyes than in phakic eyes. ${ }^{8-13}$

Pars plana vitrectomy is increasingly being employed in the treatment of rhegmatogenous retinal detachments. Current indications include the presence of advanced proliferative vitreoretinopathy, ${ }^{14}$ retinal breaks that are technically difficult to treat with scleral buckles (giant retinal tears, macular breaks, large or posterior horseshoe tears, and complex arrangements of retinal breaks) ${ }^{15-18}$ and poor retinal visualisation due to media opacities. ${ }^{17-19}$ Vitrectomy can also facilitate the detection of obscure retinal breaks when none are identified pre-operatively by enabling an internal search with deep scleral indentation. ${ }^{17,18,20}$

Primary vitrectomy for pseudophakic and aphakic retinal detachments may improve the primary retinal reattachment rate by enabling better identification of the causative retinal breaks. Advantages of this surgical approach include improved visualisation of the peripheral retina (facilitated by removal of any opacities in the anterior segment) and an internal search for obscure retinal breaks with deep scleral indentation. ${ }^{17,18,20}$ Vitrectomy is not complicated by post-operative cataract in these non-phakic eyes. This study reports the results of primary vitrectomy in a series of pseudophakic and aphakic retinal detachments.

\section{Patients and methods}

A prospective study was performed to investigate primary vitrectomy for the treatment of pseudophakic and aphakic retinal detachments. Twenty-five consecutive patients (25 eyes) were treated at the West Norwich Hospital during the 2-year period January 1995 to December 1996. There were 20 pseudophakic and 5 aphakic retinal detachments. Patients had a median age of 73 years (range 33-92 years). There were 13 men and 12 women.. Patients were followed for at least 6 months postoperatively (median 10 months, range 7-27 months).
D.K. Newman

R.L. Burton

Department of

Ophthalmology West Norwich Hospital Bowthorpe Road Norwich NR2 3TU, UK

D.K. Newman, MA, FRCOphth Department of Ophthalmology Clinic 3 (Box 41) Addenbrooke's Hospital Hills Road

Cambridge CB2 2QQ, UK Tel: +44 (0)1223 245151 Fax: +44 (0)1223 217968

Sources of funding: None

Proprietary or financial interests: None

Received: 8 January 1999 Accepted in revised form: 4 June 1999 
Table 1. Characteristics of retinal detachments

\begin{tabular}{lc}
\hline Characteristic & No. \\
\hline Macula on & 7 \\
Extent of retinal detachment: & 13 \\
2 quadrants & 10 \\
3 quadrants & 2 \\
4 quadrants & 13 \\
Number of retinal breaks: & 11 \\
Single & 1 \\
Multiple & \\
None identified & 3 \\
Proliferative vitreoretinopathy: & \\
Nil & 11 \\
Grade A & 7 \\
Grade B & 4 \\
Grade C-1
\end{tabular}

All patients had a primary rhegmatogenous retinal detachment (Table 1). Details regarding previous cataract surgery in the affected eye are given in Table 2 . The median interval between cataract surgery and retinal detachment was 3.1 years (range 10 months to 31 years). Patients were excluded if they had advanced proliferative vitreoretinopathy (grade C-3 or worse ${ }^{21}$ ), giant retinal tear, macular break, proliferative diabetic retinopathy, endophthalmitis, severe ocular trauma, or end-stage glaucoma.

All eyes underwent a three-port pars plana vitrectomy by a single surgeon (R.L.B.) using an operating microscope with a standard set of contact lenses. A wide angle viewing system was not employed. A complete vitrectomy was performed, including removal of the anterior vitreous gel aided by scleral indentation. An internal search for retinal breaks was conducted with inspection of the peripheral retina by deep scleral indentation. Subretinal fluid was drained internally through a retinal break in 21 eyes and externally in 3 eyes. Subretinal fluid was not drained in one eye. Perfluorodecalin was used in one eye to assist an internal search for retinal breaks, which proved unsuccessful. Perfluorodecalin was employed in 2 further eyes to stabilise the posterior retina during surgery.

Table 2. Previous cataract surgery in eye with retinal detachment

\begin{tabular}{lr}
\hline Details of previous cataract surgery & No. \\
\hline Technique of cataract surgery: & 13 \\
Extracapsular cataract extraction & 6 \\
Phacoemulsification cataract extraction & 4 \\
Intracapsular cataract extraction & 2 \\
Needling (for congenital cataract) & \\
Type of intraocular lens: & 15 \\
Posterior chamber intraocular lens & 4 \\
Anterior chamber intraocular lens & 1 \\
Iris-fixated intraocular lens & 5 \\
None (aphakic) & 5 \\
Vitreous loss complicating extracapsular or & \\
phacoemulsification cataract extraction & 7 \\
Nd:YAG posterior capsulotomy & 6 \\
Myopia $\geqslant-6.00$ D (before cataract surgery) & 2 \\
Congenital cataract &
\end{tabular}

After fluid-air exchange, retinopexy was achieved by indirect laser photocoagulation (9 eyes), endolaser, photocoagulation (8 eyes), or transscleral cryotherapy (7 eyes). A combination of endolaser photocoagulation and transscleral cryotherapy was used in one eye. Internal tamponade of retinal breaks was achieved with $20 \% \mathrm{SF}_{6}$. Scleral buckles were used in 12 eyes, including all eyes with inferior retinal breaks and proliferative vitreoretinopathy grade $\mathrm{C}-1$. Scleral buckling comprised an encircling band (5 eyes), an encircling band with local explant (5 eyes), and a local explant (2 eyes).

Visualisation of the peripheral retina was impaired in $17(68 \%)$ eyes. This was due to capsular opacification $(6$ eyes), small pupil (6 eyes), capsular opacification + reflexes from intraocular lens ( 3 eyes), cortical lens remnants ( 1 eye), and small pupil + capsular opacification (1 eye). Procedures to improve visualisation were performed at surgery in $7(28 \%)$ eyes: posterior capsulectomy (4 eyes), pupil enlargement with iris hooks ( 2 eyes), and removal of iris-fixated intraocular lens ( 1 eye).

\section{Results}

\section{Retinal reattachment}

The primary retinal reattachment rate following vitrectomy was $84 \%$ ( 21 eyes). The reasons for surgical failure were new/missed retinal breaks ( 2 eyes) and proliferative vitreoretinopathy (2 eyes). A final retinal reattachment rate of $96 \%$ (24 eyes) was achieved with further surgery.

Both the recurrent retinal detachments due to new / missed retinal breaks were successfully treated with one further procedure. Pneumatic retinopexy was performed in one case. Retinopexy with scleral buckling and $\mathrm{SF}_{6}$ internal tamponade was performed in the other case. Visualisation of the peripheral retina had been impaired in this eye due to a small pupil.

Proliferative vitreoretinopathy grade $\mathrm{C}-1$ produced a recurrent retinal detachment in one eye due to opening of a treated retinal break in previously flat inferior retina. This patient required two further procedures to achieve retinal reattachment comprising preretinal membrane removal, scleral buckling and silicone oil internal tamponade. Proliferative vitreoretinopathy grade C-3 produced a recurrent retinal detachment in another eye due to reopening of the original retinal breaks. This patient declined further surgery.

\section{Visual outcome}

The best corrected visual acuity of patients following retinal reattachment is given in Table 3 . All patients with a macula-on detachment retained their presenting visual acuity. The patient with a post-operative visual acuity of $6 / 60$ had a pre-existing disciform macular scar due to age-related macular degeneration. A visual acuity of $6 / 18$ or better was achieved by $10(56 \%)$ patients with a macula-off detachment. 
Table 3. Best corrected visual acuity following retinal reattachment

\begin{tabular}{lcc}
\hline Visual acuity & $\begin{array}{c}\text { Macula-on } \\
\text { detachments }\end{array}$ & $\begin{array}{c}\text { Macula-off } \\
\text { detachments }\end{array}$ \\
\hline $6 / 6$ & 1 & 1 \\
$6 / 9$ & 3 & 2 \\
$6 / 12$ & 2 & 3 \\
$6 / 18$ & - & $4^{c}$ \\
$6 / 24$ & - & - \\
$6 / 36$ & - & $3^{b, d}$ \\
$6 / 60$ & $1^{a}$ & $1^{(b+c)}$ \\
Counting fingers & - & $3^{b, c, e}$ \\
Hand movements & - & $1^{f}$ \\
\hline
\end{tabular}

Identified causes of reduced post-operative visual acuity: ${ }^{a}$ preexisting disciform macular scar; ${ }^{b}$ chronic retinal detachment $(>2$ months duration); ${ }^{c}$ macular pucker; ${ }^{d}$ macular hole; ${ }^{e_{i n t r a-}}$ operative submacular choroidal haemorrhage; ${ }^{f}$ anatomical failure.

\section{Retinal break detection at surgery}

Table 4 compares retinal break detection at surgery with the pre-operative findings. No retinal break could be identified at the pre-operative examination in 9 eyes (7 eyes had poor visualisation of the peripheral retina). Retinal breaks were detected in 8 of these eyes at surgery. However, no retinal break was detected in one eye despite a posterior capsulectomy to improve visualisation and an internal search using both deep scleral indentation and perfluorodecalin to express the Schlieren phenomenon. While retinal breaks were identified at the pre-operative examination in the remaining 16 eyes, additional retinal breaks were detected at surgery in 8 of these eyes ( 6 eyes had poor visualisation of the peripheral retina).

\section{Intra-operative complications}

Iatrogenic retinal breaks occurred in 3 eyes, but these did not compromise the surgical outcome in any case. One eye developed a submacular choroidal haemorrhage due to hypotony when an infusion line became blocked during surgery. The consequent macular sac reduced the post-operative visual acuity to counting fingers. External drainage of subretinal fluid was complicated in one eye by a localised subretinal haemorrhage extending to the temporal arcade vessels.

\section{Post-operative complications}

The post-operative complications are given in Table 5 . Macular pucker developed in 3 eyes. In one case, however, this occurred after surgery for a recurrent retinal detachment due to proliferative vitreoretinopathy.

Raised intraocular pressure $(\geqslant 30 \mathrm{mmHg})$ was the most common post-operative complication, affecting 10 eyes in the early post-operative period. The intraocular pressure was considerably elevated $(\geqslant 50 \mathrm{mmHg}$ ) in 4 eyes but resulted in no adverse sequelae. Five patients developed chronic elevation of intraocular pressure $(\geqslant 30 \mathrm{mmHg})$, which required treatment in 4 cases. Two of these patients were known to have pre-existing ocular hypertension affecting both eyes.

Pupil capture occurred in one eye that was successfully corrected on the first post-operative day. This eye had a sulcus-fixated posterior chamber intraocular lens with a central defect in the posterior capsule. Explant extrusion occurred in one patient at 16 months after surgery.

\section{Discussion}

In this study, primary vitrectomy for pseudophakic and aphakic retinal detachments achieved a primary retinal reattachment rate of $84 \%$ ( $21 / 25$ eyes). The potential advantages of this surgical approach include improved visualisation of the peripheral retina (facilitated by removal of any opacities in the anterior segment) and an internal search for obscure retinal breaks with deep scleral indentation. ${ }^{17,18,20}$ Visualisation of the peripheral retina was impaired in $17(68 \%)$ eyes in this study and procedures to improve visualisation were performed in 7 (28\%) eyes. At surgery, retinal breaks were detected in 16 $(64 \%)$ eyes that had not been identified pre-operatively (no retinal break was identified pre-operatively in 8 of these eyes). Visualisation of the peripheral retina was impaired in most, but not all, of these eyes. An internal search for retinal breaks may therefore be advantageous even in eyes with good visualisation of the peripheral retina. ${ }^{10,22}$

Primary vitrectomy can also produce adverse effects such as iatrogenic damage to the retina, post-operative elevation of intraocular pressure, and rarely endophthalmitis. ${ }^{23}$ Post-operative cataract is not a complication in non-phakic eyes. Iatrogenic retinal

Table 4. Detection of additional retinal break(s) at surgery

\begin{tabular}{lcc}
\hline & & Additional retinal break(s) detected at surgery \\
\cline { 2 - 3 } Pre-operative findings & None detected & Additional retinal break(s) detected \\
\hline No retinal break identified & 0 & 2 \\
Good visualisation of peripheral retina & 1 \\
Poor visualisation of peripheral retina & 6 \\
Retinal break(s) identified & 4 \\
Good visualisation of peripheral retina & 4 \\
Poor visualisation of peripheral retina & 2 \\
\hline
\end{tabular}




\begin{tabular}{|c|c|c|c|c|c|}
\hline \multirow[b]{2}{*}{ Patient no. } & \multirow[b]{2}{*}{ Retinal re-detachment } & \multirow[b]{2}{*}{ Macular pucker } & \multicolumn{3}{|c|}{ Raised IOP $(\geqslant 30 \mathrm{mmHg})$ at: $^{a}$} \\
\hline & & & 1 day & 2 weeks & $\geqslant 6$ months \\
\hline 1 & + & - & - & - & - \\
\hline 2 & + & - & ++ & + & - \\
\hline 3 & $+($ PVR) & + & - & - & + \\
\hline 4 & $+(\mathrm{PVR})^{b}$ & - & - & - & - \\
\hline 5 & - & + & - & - & - \\
\hline 6 & - & + & - & - & $t^{\mathrm{c}}$ \\
\hline 7 & - & - & ++++ & + & - \\
\hline 8 & - & - & +++ & - & - \\
\hline 9 & - & - & ++ & +++ & + \\
\hline 10 & - & - & ++ & +++ & - \\
\hline 11 & - & - & ++ & + & $+^{c}$ \\
\hline 12 & - & - & ++ & - & - \\
\hline 13 & - & - & + & - & - \\
\hline 14 & - & - & + & - & - \\
\hline 15 & - & - & - & ++ & - \\
\hline 16 & - & - & - & - & + \\
\hline Total & 4 & 3 & 9 & 6 & 5 \\
\hline
\end{tabular}

$\mathrm{PVR}$, proliferative vitreretinopathy; IOP, intraocular pressure.

${ }^{a}$ Level of raised IOP: $+=\mathrm{IOP} \geqslant 30 \mathrm{mmHg},++=\mathrm{IOP} \geqslant 40 \mathrm{mmHg},+++=\mathrm{IOP} \geqslant 50 \mathrm{mmHg},++++=\mathrm{IOP} \geqslant 60 \mathrm{mmHg}$.

${ }^{b}$ Retinal reattachment was not achieved.

${ }^{c}$ Patient had pre-existing ocular hypertension and IOP was elevated $(\geqslant 30 \mathrm{mmHg}$ ) in both eyes at $\geqslant 6$ months post-operatively.

breaks occurred in 3 eyes in this study, but none compromised the surgical outcome because they were recognised and treated at surgery. The only significant per-operative complication was a submacular choroidal haemorrhage that developed in one eye due to intraoperative hypotony. In general, however, vitrectomy does have the advantage of providing a controlled intraocular environment throughout surgery. Scleral buckling procedures probably have a greater (though still small) risk of submacular choroidal haemorrhage associated with external drainage of subretinal fluid. ${ }^{24,25}$

Post-operative elevation of intraocular pressure is common following vitrectomy and gas internal tamponade. ${ }^{26}$ In accord with previous reports, ${ }^{23}$ elevated intraocular pressure $(\geqslant 30 \mathrm{mmHg})$ affected $10(40 \%)$ eyes in the early post-operative period in this study. Four eyes developed greatly elevated intraocular pressure $(\leqslant 50 \mathrm{mmHg}$ ) but without any adverse sequelae. Chronic elevation of intraocular pressure occurred in $5(20 \%)$ eyes, though 2 of these cases had pre-existing ocular hypertension and 1 case was associated with proliferative vitreoretinopathy. ${ }^{27}$ The incidence of postoperative proliferative vitreoretinopathy $(8 \%)$ and macular pucker $(12 \%)$ in this study was fairly typical for primary retinal detachment surgery. ${ }^{23}$

Pars plana vitrectomy already has an established role in the treatment of certain retinal detachments that were therefore excluded from this study. These comprise advanced proliferative vitreoretinopathy, ${ }^{14}$ retinal breaks that are technically difficult to treat with scleral buckles (giant retinal tears, macular breaks, large or posterior horseshoe tears, and complex arrangements of retinal breaks), ${ }^{15-18}$ and poor retinal visualisation due to media opacities. ${ }^{17-19}$ Scleral buckling was a feasible alternative to primary vitrectomy for every patient included in the study. A relative indication for primary vitrectomy was present in 3 patients who had superior bullous retinal detachments due to a retinal break of one clock-hour in size, but each of these cases could have been treated by a scleral buckling procedure. ${ }^{28}$ While many patients had impaired visualisation of the peripheral retina due to capsular opacification or cortical lens remnants, this was never severe enough to totally preclude retinal visualisation thereby requiring a vitrectomy.

One previous study has investigated the role of primary vitrectomy in the treatment of pseudophakic retinal detachments. ${ }^{29}$ Every patient in this series of 33 eyes underwent a standardised surgical procedure using the operating microscope with a wide angle viewing system. This comprised placement of an encircling band at $13 \mathrm{~mm}$ from the limbus to support the vitreous base, pars plana vitrectomy, injection of perfluorodecalin to stabilise the central retina during examination of the vitreous base, internal drainage of subretinal fluid through a retinal break, endolaser photocoagulation to the retinal break(s) and $360^{\circ}$ on the encircling buckle, and internal tamponade with $\mathrm{C}_{3} \mathrm{~F}_{8}$. With this comprehensive surgical approach, a primary retinal reattachment rate of $94 \%$ was achieved. At surgery, retinal breaks were detected in $20(61 \%)$ eyes that had not been identified pre-operatively (no retinal break was identified preoperatively in 9 of these eyes). Failure to identify any retinal break at surgery occurred in 2 eyes. These results are very similar to the findings of our study.

For both this study ${ }^{29}$ and our series, a limitation exists in the methodology for assessing the improvement in retinal break detection resulting from primary vitrectomy. Comparison was made between retinal breaks identified at the pre-operative examination and those detected at surgery. However, a more appropriate baseline comparison would be retinal breaks identified by indirect ophthalmoscopy with scleral depression 
under anaesthesia, since this may reveal retinal breaks not detected at a pre-operative examination. Such retinal breaks would have been identified and treated by scleral buckling procedures. Another issue that remains unresolved is the precise indication for scleral buckling in association with primary vitrectomy for retinal detachment. ${ }^{30}$ Scleral buckling may have an associated ocular morbidity and further studies are required to define its role in these cases.

In conclusion, primary vitrectomy can achieve good results in the treatment of pseudophakic and aphakic retinal detachments. The primary retinal reattachment rate is of great importance in the assessment of retinal detachment surgery since it is generally associated with a better visual outcome and reduced patient morbidity. ${ }^{30}$ A wide range of primary retinal reattachment rates has been reported in recent studies for scleral buckling procedures in both pseudophakic $(49 \% \text { to } 84 \%)^{2-7}$ and aphakic $(62 \% \text { to } 82 \%)^{3,7}$ retinal detachments. Comparison between our study and these series is difficult due to the presence of multiple confounding factors. In particular, there have been varying indications for the selective use of vitrectomy in series treated predominantly by scleral buckling procedures. A controlled study will therefore be required to determine whether primary vitrectomy achieves a better outcome than scleral buckling procedures for pseudophakic and aphakic retinal detachments.

\section{References}

1. McHugh D, Wong D, Chignell A, Leaver P, Cooling R. Pseudophakic retinal detachment. Graefes Arch Clin Exp Ophthalmol 1991;229:521-5.

2. Greven CM, Sanders RJ, Brown GC, Annesley WH, Sarin LK, Tasman W, Morgan TM. Pseudophakic retinal detachments: anatomic and visual results. Ophthalmology 1992;99:257-62.

3. Yoshida A, Ogasawara H, Jalkh AE, Sanders RJ, McMeel JW, Schepens CL. Retinal detachment after cataract surgery: surgical results. Ophthalmology 1992;99:460-5.

4. Lake S, Dereklis D, Georgiadis N, Alexandridis A, Economidis P. Management of pseudophakic retinal detachment with various intraocular lens types. Ann Ophthalmol 1993;25:381-4.

5. Frau E, Sam H, Korobelnik JF, Chauvaud D. Retinal detachment after cataract surgery: retrospective study of 57 cases. Eur J Ophthalmol 1993;3:177-80.

6. Girard P, Karpouzas I. Pseudophakic retinal detachment: anatomic and visual results. Graefes Arch Clin Exp Ophthalmol 1995;233:324-30.

7. Berrod JP, Sautiere B, Rozot P, Raspiller A. Retinal detachment after cataract surgery. Int Ophthalmol 1997;20:301-8.

8. Laatikainen L, Harju H, Tolppanen EM. Postoperative outcome in rhegmatogenous retinal detachment. Acta Ophthalmol 1985;63:647-55.

9. Törnquist R, Bodin L, Törnquist P. Retinal detachment: a study of a population-based patient material in Sweden 1971-1981. IV. Prediction of surgical outcome. Acta Ophthalmol 1988;66:637-42.
10. Tornambe PE, Hilton GF. Pneumatic retinopexy: a multicenter randomized controlled clinical trial comparing pneumatic retinopexy with scleral buckling. The Retinal Detachment Study Group. Ophthalmology 1989;96:772-83.

11. Bossung C, Muller K, Heiland E, Richard G. Success of retinal surgery comparing phakic and pseudophakic eyes with reference to preoperative findings and the kind of lens implant. Klin Monatsbl Augenheilkd 1992;201:79-82.

12. Grizzard WS, Hilton GF, Hammer ME, Taren D. A multivariate analysis of anatomic success of retinal detachments treated with scleral buckling. Graefes Arch Clin Exp Ophthalmol 1994;232:1-7.

13. Sharma T, Challa JK, Ravishankar KV, Murugesan R. Scleral buckling for retinal detachment: predictors for anatomic failure. Retina 1994;14:338-43.

14. The Silicone Study Group. Vitrectomy with silicone oil or perfluoropropane gas in eyes with severe proliferative vitreoretinopathy: results of a randomized clinical trial. Silicone Study Report 2. Arch Ophthalmol 1992;110:780-92.

15. Billington BM, Leaver PK. Vitrectomy and fluid/silicone oil exchange for giant retinal tears: results at 18 months. Graefes Arch Clin Exp Ophthalmol 1986;224:7-10.

16. Gonvers $M$, Machemer R. A new approach to treating retinal detachment with macular hole. Am J Ophthalmol 1982;94:468-72.

17. Gartry DS, Chignell AH, Franks WA, Wong D. Pars plana vitrectomy for the treatment of rhegmatogenous retinal detachment uncomplicated by advanced proliferative vitreoretinopathy. Br J Ophthalmol 1993;77:199-203.

18. Hakin KN, Lavin MJ, Leaver PK. Primary vitrectomy for rhegmatogenous retinal detachment. Graefes Arch Clin Exp Ophthalmol 1993;231:344-6.

19. Wong D, Billington BM, Chignell AH. Pars plana vitrectomy for retinal detachment with unseen retinal holes. Graefes Arch Clin Exp Ophthalmol 1987;225:269-71.

20. Rosen PH, Wong HC, McLeod D. Indentation microsurgery: internal searching for retinal breaks. Eye 1989;3:277-81.

21. The Retina Society Terminology Committee. The classification of retinal detachment with proliferative vitreoretinopathy. Ophthalmology 1983;90:121-5.

22. Grizzard WS, Hilton GF, Hammer ME, Taren D, Brinton DA. Pneumatic retinopexy failures: cause, prevention, timing, and management. Ophthalmology 1995;102:929-36.

23. Wilkinson CP, Rice TA. Michels retinal detachment. 2nd ed. St Louis: Mosby, 1997.

24. Wilkinson CP, Bradford RH. Complications of draining subretinal fluid. Retina 1984;4:1-4.

25. Piper JG, Han DP, Abrams GW, Mieler WF. Perioperative choroidal hemorrhage at pars plana vitrectomy: a casecontrol study. Ophthalmology 1993;100:699-704.

26. Han DP, Lewis H, Lambrou FH, Mieler WF, Hartz A. Mechanisms of intraocular pressure elevation after pars plana vitrectomy. Ophthalmology 1989;96:1357-62.

27. Barr CC, Lai MY, Lean JS, Linton KL, Trese M, Abrams G, Ryan SJ, Azen SP. Postoperative intraocular pressure abnormalities in the Silicone Study. Silicone Study Report 4. Ophthalmology 1993;100:1629-35.

28. Gilbert C, McLeod D. D-ACE surgical sequence for selected bullous retinal detachments. Br J Ophthalmol 1985;69:733-6.

29. Bartz-Schmidt KU, Kirchhof B, Heimann K. Primary vitrectomy for pseudophakic retinal detachment. Br J Ophthalmol 1996;80:346-9.

30. Leaver P. Expanding the role of vitrectomy in retinal reattachment surgery. Br J Ophthalmol 1993;77:197. 